\title{
Un sistema de actividad para la diagramación argumental con TIC: ¿podemos hablar de innovación educativa?
}

\author{
Federico Ferrero \\ federicojferrero@gmail.com \\ Universidad Nacional de Córdoba, CONICET, Argentina
}

Adriana Gewerc

adriana.gewerc@gmail.com

Universidad de Santiago de Compostela, Spain

\begin{abstract}
Resumen
El Enfoque Sociocultural de los aprendizajes entiende que todo sistema de actividad se transforma cuando así lo hacen su objeto y su motivo. A partir de allí, este artículo analiza la dinámica de constitución, desarrollo y posible transformación de un sistema de actividad de diagramación argumental que utiliza el software Araucaria en clases de Lógica Informal (Facultad de Filosofía y Humanidades, FFyH, Universidad Nacional de Córdoba, UNC, Argentina). Desde una metodología mixta, se aborda un estudio de caso en el cual se realiza observación no participante durante un semestre. Los resultados sugieren que Araucaria promueve el aprestamiento técnico y la eficiencia en la manipulación diagramática, aunque no se observan indicios de transformación del contenido a aprender. Solamente se advierte el traslado de un sistema diagramático clásico (arbóreo) a un entorno virtual, junto con el agregado de un nuevo conjunto de acciones independientes de las motivaciones que fundan el sistema de actividad "tradicional".
\end{abstract}

\section{Palabras Clave}

Sistema de actividad; lógica informal; diagramación argumental; software educativo. 


\title{
An activity system for argument diagramming with ICT: can we talk about educational innovation?
}

\author{
Federico Ferrero \\ federicojferrero@gmail.com \\ Universidad Nacional de Córdoba, CONICET, Argentina \\ Adriana Gewerc \\ adriana.gewerc@gmail.com \\ Universidad de Santiago de Compostela, Spain
}

\begin{abstract}
The Sociocultural Approach to learning understands that every activity system is transformed when its object and its motive do so. From this, the article analyzes the dynamics of constitution, development and possible transformation of the argument diagramming system that uses Araucaria software in Informal Logic classes (School of Philosophy and Humanities, FFyH, National University of Cordoba, UNC, Argentina). From a mixed perspective, a case study is conducted in which non-participant observation has been performed during a semester. The results suggest that Araucaria promotes technical knowledge and the efficiency in diagrammatic manipulation, although there is not transformation evidence of the content to be learned. It is only observed the transfer of a classic diagramming system (arboreal) to a virtual environment together with the addition of a new actions-set independent of motivations that found the "traditional" activity system.
\end{abstract}

\section{Keywords}

Activity system; informal logic; argument diagramming; educational software 


\section{Introducción}

La preocupación actual por la calidad de los conocimientos que se construyen en la universidad contempla discusiones que valoran a la argumentación, a las habilidades de razonamiento y al "Pensamiento Crítico" como vías privilegiadas para la formación de nuevas generaciones de estudiantes (Davies \& Barnett, 2015; Dunn, Halonen \& Smith, 2008; Hitchcock, 2017; Huber \& Kuncel, 2016; Hughes \& Lavery, 2015; Khun, 2012; McPeck, 2016).

Al mismo tiempo, el avance general de las condiciones materiales de acceso tecnológico en las instituciones educativas ha mostrado no ser suficiente per se para estimular la innovación pedagógica. En este sentido, distintos autores señalan que aún hoy continúan hallándose dificultades vinculadas a la idea de "soluciones tecnológicas mágicas" cuando las propuestas docentes se dirigen a enriquecer las prácticas educativas con esas nuevas tecnologías (Cuban, 2001; Dussel \& Trujillo Reyes, 2018; Lion, 2006; Maggio, 2012).

En este contexto, surge la inquietud por analizar el uso efectivo de aplicaciones de software que, insertas en determinados escenarios, permiten hablar de innovación educativa cuando estudiantes universitarios desarrollan habilidades de razonamiento al diagramar argumentos. Esta pregunta tiene sentido en tanto reconocemos que si bien se han desarrollado múltiples softwares con este propósito didáctico (Scheuer, Loll, Pinkwart \& MacLaren, 2010), es escasa la investigación sobre sus usos efectivos analizados desde las coordenadas teóricas del Enfoque Sociocultural de los aprendizajes.

Considerando esta problemática esta investigación tiene como objetivo describir y analizar la dinámica de constitución, desarrollo y posible transformación del sistema de actividad de diagramación argumental que se establece cuando se utiliza el software Araucaria en la enseñanza de Lógica Informal (Facultad de Filosofía y Humanidades, FFyH, Universidad Nacional de Córdoba, UNC, Argentina).

La pregunta de investigación se dirige a explorar qué le aporta el uso de este software a la diagramación de argumentos considerando los principios y preguntas que gobiernan a los "sistemas de actividad" (Engeström, 2000; 2001 ; 2001 ; 2015). Es decir que la interrogación convoca a dar cuenta del tipo de prácticas que el software educativo promueve y de los modos con los que los participantes usan los recursos en un sistema social y material situado y complejo (Chaiklin \& Lave, 2001; Lave, 2015; Wenger, 2001).

Si revisamos los modelos conceptuales utilizados para describir, analizar y evaluar software educativo hallamos un panorama poco alentador. Frecuentemente, se observan clasificaciones de entornos virtuales definidas por categorías ad hoc, cierto a-teoricismo en la orientación de los estudios, poca especificidad en el análisis de las posibilidades educativas y una clara sobredimensión de las características técnicas de las herramientas digitales (véanse críticas en Lantz-Andersson, Linderoth \& Säljö, 2009; Luppinici, 2007; Twining, 2002). Sumado a ello y, en términos generales, se indica una propensión en Tecnología Educativa a formular preguntas de investigación que abordan de modo simplificado, es decir utilizando modelos lineales causaefecto, los beneficios que traería el uso de estas herramientas sobre los aprendizajes (Gros, 2016).

En este marco, el presente estudio pretende superar estos obstáculos proponiendo el análisis de un sistema de actividad de diagramación de argumentos con tecnología digital desarrollado durante un semestre de un curso de estudios universitarios. En particular, se trata de estudiantes cuya actividad semiótica e instrumentalmente mediada se dirige, con el apoyo del docente, al dominio de la diagramación de argumentos que, en el sistema, toma la posición de objeto de aprendizaje. El abordaje, si bien considera todos los elementos de la unidad de 
análisis vigotskyana, centra la mirada en el instrumento mediador y pone énfasis en la perspectiva de los actores que están involucrados en la situación. Intenta así avanzar en la reconstrucción de la evolución y dinámica de funcionamiento del sistema de actividad particular.

Para situar esta indagación, es imprescindible reconocer que las investigaciones sobre el uso de software específico en contextos de aprendizaje han sido abordadas desde variados enfoques. Entre ellos, uno de los estudios clásicos ha sido desarrollado por Squires y McDougall (2001) para sentar las bases de lo que denominan la "interacción de perspectivas". Estos autores analizan los intercambios entre docentes, diseñadores y estudiantes que utilizan software y proponen el movimiento de la atención desde los atributos técnicos de las herramientas hacia los usos que de ellas se hace (estimulantes y, a la vez, imprevistos por los diseñadores, entre otros).

Otro grupo de antecedentes de interés está representado por el trabajo de César Coll y su equipo de estudio de las Tecnologías de la Información y la Comunicación (TIC) como instrumentos de mediación. En su caso, examinan la distinción entre los usos planificados y los usos efectivos de estas herramientas, revelan una cierta "subutilización" de las potencialidades tecnológicas en los contextos áulicos y reconocen la reproducción de patrones de acción muy similares a los que se encuentran sin el uso de las herramientas digitales (etcétera) (Coll, 2004; Coll, Onrubia \& Mauri, 2007; Coll, Mauri \& Onrubia, 2008; Coll \& Monereo, 2008).

Finalmente, los estudios llevados a cabo por el grupo de investigadores suecos establecidos alrededor de Roger Säljö constituye otro conjunto de antecedentes relevantes dada la riqueza del trabajo empírico producido en torno al aprendizaje de objetos formales desde la perspectiva vigotskyana. En sus trabajos, identifican los marcos de referencia (matemático, informático, etc.) que se van activando en situaciones de aprendizaje con software y encuentran que las tecnologías digitales agregan nuevas reglas a las situaciones haciéndolas más complejas y codeterminando la dificultad de resolución de tareas (Lantz-Andersson, 2009; Lantz-Andersson et al., 2009; Säljö, Eklund \& Mäkitalo, 2006; Säljö \& Wyndham, 2001).

En resumen, este conjunto de antecedentes identifica tipos de interacciones de los sujetos cuando usan tecnologías digitales para aprender, distingue usos planeados y efectivos (v.gr subutilización) y comprende la complejidad de la inserción de tales herramientas digitales en contextos situados y dedicados al aprendizaje de objetos formales.

Sobre estas bases, este estudio aborda los desarrollos producidos por Leontiev y Engeström en el marco del "Enfoque Sociocultural" de investigación sobre los aprendizajes (Matusov, 2008). Luego, con especial énfasis en la multi-vocalidad del sistema, se presenta el trabajo de observación de clases y su análisis. Finalmente, en las conclusiones, se discuten algunas hipótesis en torno a los posibles ciclos expansivos de transformación sistémica que podrían estimularse en el caso del sistema de actividad de la diagramación con software.

\section{EI Enfoque Sociocultural en Teorías del Aprendizaje}

En el caso del Enfoque Sociocultural de los aprendizajes, la propuesta de un giro "situacional" o "contextualista" en la definición de una unidad de análisis apropiada ha demarcado claras distinciones entre las Teorías del Aprendizaje del siglo XX.

A diferencia de las perspectivas cognitivas clásicas y de las aproximaciones conductistas de los aprendizajes (véanse críticas en Chaiklin \& Lave, 2001; Vigotsky, 1998); la tradición Sociocultural pondera que el "individuo" es una unidad insuficiente para abordar sus modos de 
aprender y que su definición no debe entenderse de manera sustancial ni fija. En efecto, la perspectiva vigotskyana decanta en un núcleo teórico que puede resumirse, siguiendo a Wertsch, en torno a tres temas centrales:

1) la creencia en el método genético o evolutivo; 2) la tesis de que los procesos psicológicos superiores tienen su origen en procesos sociales y 3) la tesis de que los procesos mentales pueden entenderse solamente mediante la comprensión de los instrumentos y signos que actúan de mediadores (1995, p. 32).

En este marco, la unidad de análisis vigotskyana "genérica" es definida como la "actividad intersubjetiva semióticamente mediada" según un conjunto de definiciones teóricometodológicas que tienen claros efectos sobre la tarea investigativa (Vigotsky, 2009; 2010).

Sin embargo, este enfoque aloja variaciones de la unidad de análisis primigenia conforme distintos desarrollos teóricos posteriores y enfáticos de diversos elementos y relaciones. Es posible, entonces, referenciar cronológicamente a las unidades de análisis correspondientes a tres generaciones de producción teórica de la línea Sociocultural que Engeström identifica $\left(2001^{a}\right)$ : la primera generación alrededor de los trabajos pioneros de Vigotsky; la segunda generación en torno a los desarrollos de Leontiev; y la tercera generación integrada por neovigotskyanos.

En este trabajo, a partir de la unidad de análisis propuesta por Vigotsky en "el segundo momento de su obra" (según periodiza González Rey, 2010), nos concentraremos en los desarrollos de la Teoría de la Actividad o CHAT (Cultural Historical Activity Theory). Puntualmente, profundizaremos en los aportes de Leontiev y Engeström. Sus conceptos, servirán como herramientas para abordar el análisis del caso.

\section{a. La segunda generación: Leontiev}

A finales de los años 70 Leontiev precisó el concepto de "actividad" como la unidad de análisis psicológico y, con él, avanzó en dar respuestas a las limitaciones adjudicadas a los trabajos vigotskyanos.

La principal objeción realizada a la primera generación de la línea Sociocultural fue que la unidad de análisis que proponía estaba circunscripta a las acciones individuales (Engeström, $2001^{a}$ ). Ante este problema, Leontiev mostró que la actividad es una formación colectiva y sistémica, con una compleja estructura mediadora que no es reductible a un mero proceso de adición de un conjunto enumerado de acciones individuales (1984).

Con el famoso ejemplo de la "caza colectiva primitiva", Leontiev objetivó la distinción entre acciones individuales y actividad colectiva. Sostuvo que cuando los integrantes de una tribu están cazando, cada uno de ellos responde a acciones con objetivos separados ("cazar", "espantar animales", etc.). No obstante, "el motivo real se encuentra más allá de la caza. El objetivo conjunto de esas personas es obtener comida y vestimenta: sobrevivir" (Leontiev, 1981, p. 62).

Desde esta óptica, el hecho de que un sistema de actividad sea producido y reproducido en y por acciones, no habilita a que la actividad general sea reducida a esas acciones agenciadas individualmente. La actividad es en sí misma un concepto distinto dado a su adscripción colectiva y a su desarrollo histórico.

Para dar cuenta de la estructura general de la actividad, Leontiev planteó la distinción analítica 
entre "actividad", "acción" y "operación", vinculando cada uno de estos niveles con los "motivos", los "fines" y los "medios o condiciones" respectivamente.

En primer lugar, define a la "actividad" por la vía de sus motivos. Señala que aquello que distingue una actividad de otra "es la diferencia de sus objetos, ya que es el objeto de la actividad el que le confiere determinada orientación" (1984, p. 82).

En segunda instancia, establece que los "componentes" principales de las actividades que llevan adelante los hombres son las "acciones" que ellos realizan. Desde su punto de vista, la acción individual responde a una tarea que supone, en definitiva, delimitar y tomar conciencia de las finalidades de esa acción: los fines definen a las acciones (Leontiev, 1984).

En tercer lugar, es necesario diferenciar el aspecto intencional y el aspecto operacional de la acción. Las "operaciones" se vinculan con las condiciones que hacen posible el uso de ciertos medios, tecnologías o procedimientos para efectuar la acción. De modo que se denomina operaciones a "los medios con los cuales se ejecuta la acción" (Leontiev, 1984, p. 85).

En resumen, los ejes que atraviesan la estructura conceptual leontieviana son dos. Por un lado, en el eje de la orientación, la actividad queda dirigida por los motivos que una comunidad encuentra para mantenerla durante el curso de la historia, y las acciones individuales se ordenan según fines particulares. Por otro lado, en el eje de la ejecución, las acciones se llevan adelante vía operaciones cuyos efectores son los medios e instrumentos.

Como se observa, esta definición teórica tiene el valor de distinguir dominios jerárquicos de la "práctica", una categoría en cuya definición se han visto incluir variados y disímiles fenómenos logrando que, en ocasiones, el concepto pierda su potencia analítica. En nuestro caso, la utilización de estas herramientas conceptuales permitirá aislar los dominios prácticos en los que aparecen novedades cuando trabajamos con el aprendizaje que incorpora tecnologías.

\section{b.La tercera generación: "neovigotskyanos"}

La tercera generación de producción teórica incluye un grupo de autores cuyos desarrollos se inscriben en la Teoría de la Actividad conforme hoy la conocemos. Tal como indica Engeström $\left(2001^{a}\right)$, desarrollos recientes en la Teoría se han dado a la tarea de responder a dos tópicos persistentes en la tradición: el de la amplitud de la escala y el del abordaje de la diversidad según un modelo de progreso distinto a su versión evolutiva y teleológica.

En el marco de estas redefiniciones conceptuales, la propuesta del propio Yrjö Engeström (2000; $\left.2001^{\mathrm{a}} ; 2001^{\mathrm{b}} ; 2015\right)$ toma el legado y las inquietudes de la segunda generación, y revisa la categoría "actividad" incluyendo más elementos al sistema triangular clásico entendido ahora como la "punta del iceberg" de la unidad analítica.

En Learning by Expanding (2015) Engeström presenta los elementos colectivos del sistema de actividad al incorporar dimensiones relativas a la "comunidad", las "reglas" y la "división del trabajo". A partir de allí, el triángulo clásico vigotskyano (sujeto - instrumento mediador objeto) se asienta sobre un piso que incorpora la comunidad cuyas prácticas se ordenan según reglas que regulan procedimientos e interacciones esperadas, y según una división del trabajo resultante de la distribución, constantemente negociada, de tareas y poderes entre los participantes (Cole \& Engeström, 2001).

Este subsuelo de la unidad de análisis es el que, finalmente, incorpora nuevos elementos y relaciones cuyo estudio permite comprensiones de los sistemas de actividad desde una definición más amplia de la escala y menos sincrónica de la operatoria con instrumentos. 
Asimismo, Engeström (2001 ) establece una serie de principios de la Teoría de la Actividad: (1) el sistema de actividad completo se toma como una unidad de análisis y no es suficiente la consideración de sólo algunos elementos y/o relaciones de dicha unidad; (2) se caracteriza por su multi-vocalidad, por la expresión de las diversas perspectivas de los actores involucrados; (3) puede ser comprendido históricamente, es decir, en su proceso de transformación; (4) las contradicciones internas del sistema tienen un rol central en tanto son fuentes de desarrollo; y (5) la posibilidad de transformación del sistema de actividad ocurre en ciclos expansivos. Interesa reseñar brevemente los dos últimos principios puesto que, alrededor de ellos, es posible analizar si ocurre la emergencia de innovaciones cuando se integran tecnologías digitales a los sistemas.

En relación con el principio cuarto, el carácter "vivo" de la unidad de análisis encuentra en las contradicciones internas a la fuerza de cambio sistémico. La noción de "perturbaciones" entendida como "desviaciones del guión estándar" de las prácticas (Engeström, 2000, p. 964)señala que la vida de los sistemas es contradictoria y discontinua. De manera que captar la vitalidad de la unidad analítica significa perseguir configuraciones expresivas de contradicciones sistémicas que podrían motorizar posibilidades de innovación.

Con base en esta apuesta, el quinto principio propuesto por Engeström es el que aborda el proceso de trasformación cualitativa de los sistemas según la metáfora de la "expansión". Esta es una imagen que "acuesta" a los procesos de desarrollo en el sentido de que ya no se los entiende en su tradicional avance verticalista y de curso único por estadios consecutivamente dispuestos, sino como procesos de "expansión" de las fronteras otrora conquistadas en el sistema de actividad. Es decir que se define la posibilidad de transformaciones expansivas a partir de esfuerzos sintéticos por superar las contradicciones acumuladas según un modelo no clásico de progreso.

En concreto, el "ciclo expansivo" comienza con un cuestionamiento por parte de individuos o grupos a la práctica consagrada. El agravamiento del conflicto, incluso la insatisfacción, es fundamental para motorizar un movimiento colectivo transformador que cristaliza cuando se completan dos condiciones. Engeström puntualiza: "Una transformación expansiva se logra cuando el objeto y el motivo de la actividad se reconceptualizan para abrazar un horizonte radicalmente más amplio de posibilidades en relación con el modo previo de actividad" (2001 ${ }^{a}$, p. 137). Se establece, en definitiva, que un ciclo completo de transformación expansiva puede entenderse como un "viaje colectivo a través de la zona de desarrollo próximo" de la actividad.

\section{El Sistema de Actividad de la diagramación de argumentos}

El aprendizaje universitario de la diagramación de argumentos con software específico es, en esta oportunidad, el sistema de actividad objeto de especificación y análisis. En particular, se trata de sujetos en posición de alumnos cuya actividad semiótica e instrumentalmente mediada se dirige, con el apoyo del docente, al dominio de la diagramación de argumentos que, en el sistema, toma la posición de objeto de aprendizaje. Este sistema de actividad (Figura 1) sólo es comprensible si se consideran, además, las reglas que lo organizan, las comunidades que lo regulan, la división de tareas típica de la institución de educación superior y la especial incorporación de un software de diagramación de argumentos como instrumento mediador. 


\section{ARTEFACTO MEDIADOR: Araucaria}

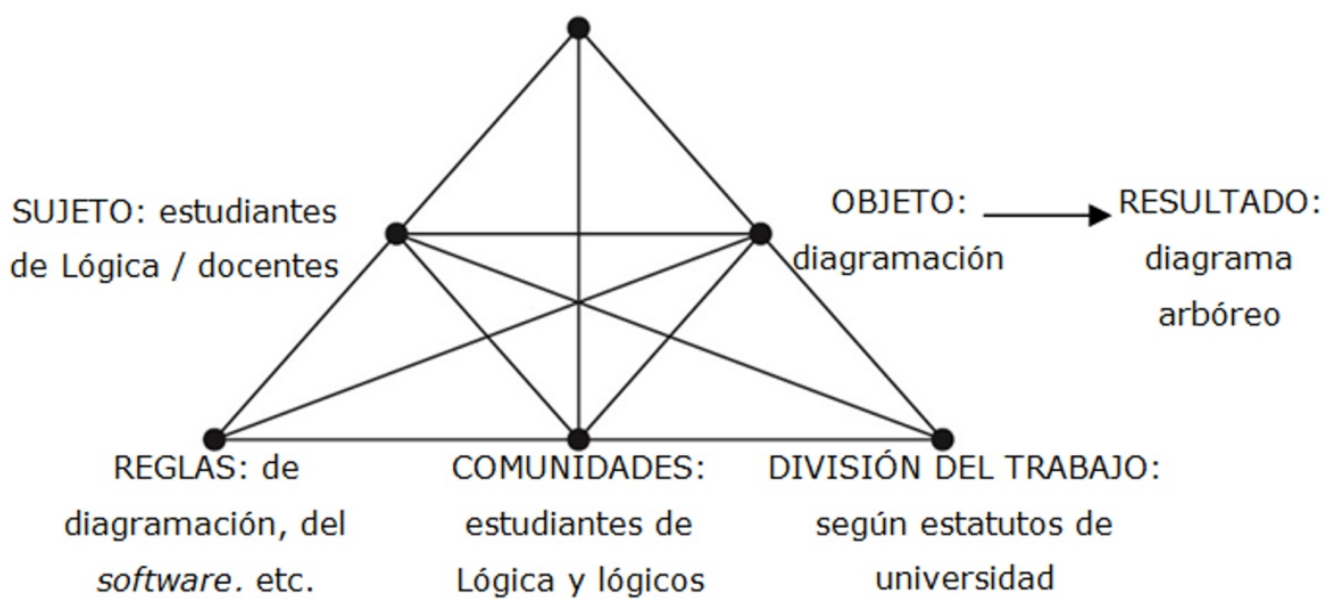

Figura 1. Sistema de actividad de diagramación de argumentos con Araucaria

Fuente: Elaboración propia de los autores a partir de Engeström (2015).

Para describir brevemente el sistema, al menos en su dimensión planeada, es posible considerar la batería de preguntas que el mismo Engeström puntualiza $\left(2001^{\mathrm{a}}\right)$. Las cuestiones incluyen interrogaciones sobre los sujetos, los motivos, los contenidos y los métodos de aprendizaje en el sistema de actividad.

La primera pregunta es la de los sujetos: "¿Quiénes son los sujetos del aprendizaje, cómo ellos están definidos y localizados?" (Engeström, 2001a , p. 133). Para dar cuenta de ello, es necesario mencionar, al menos, dos cuestiones. Por un lado, explicitar que los sujetos son 13 estudiantes del curso Lógica Informal de la Carrera de Profesorado en Filosofía (FFyH, UNC). Por otro lado, señalar que los sujetos del aprendizaje de los que hablamos son sujetos "escolarizados" en el sentido de que forman parte del dispositivo escolar moderno cristalizado en el nivel universitario de especificación. Se trata, entonces, de sujetos que se encuentran en la posición de "alumno" porque el dispositivo en el que están insertos es la organización escolar comeniana definida según principios de simultaneidad, gradualidad y universalidad.

La segunda pregunta para abordar el sistema de actividad del aprendizaje de la diagramación es "¿Qué aprenden, cuáles son los contenidos y los resultados de los aprendizajes?" (Engeström, $2001^{a}$, p. 133). Nuestra primera respuesta sostiene que el objeto del aprendizaje, al menos en su disposición ideal, es la diagramación de argumentos que obtiene como resultados, naturalmente, diagramas. Veremos más adelante si esa demarcación del contenido de la diagramación como objeto de aprendizaje se mantiene o altera.

La tercera pregunta es la de los motivos. Engeström interroga: "¿Por qué ellos aprenden, qué les hace hacer el esfuerzo?" (2001 a , p. 133). Para dar cuenta de esta inquietud es importante, en principio, considerar que desde la perspectiva de Engeström, un sujeto motivado es aquel que comprende las razones que tiene su comunidad para desarrollar una práctica específica en un sistema de actividad.

En el caso particular del curso de Lógica Informal, la noción deductivista de inferencia entre proposiciones y el carácter estructuralista de los argumentos, sostienen conceptualmente a la 
práctica de diagramación en la disciplina. Debido a ello, existen razones pedagógicas para promover la diagramación de argumentos en tanto esta práctica captura el carácter estructural y lógicamente vinculado de la arquitectura argumental. De esta manera, permite la visualización de la totalidad - gestalt y, a la vez, la manipulación de las partes constitutivas de los argumentos. Al mismo tiempo, pero con menos consenso, los diagramas en lógica se insertan como recursos "probatorios" durante el desarrollo de las clases (en el sentido de que se ofrecen como evidencias para pruebas formales). En nuestro caso y como podremos ver más adelante, el fundamento para la incorporación de los diagramas en las clases de Lógica Informal es preeminentemente de tipo pedagógico.

Finalmente, la cuarta pregunta es por el método y es enunciada del siguiente modo: "¿Cómo aprenden los sujetos, cuáles son las acciones claves o los procesos de aprendizaje?" (Engeström, $2001^{a}$, p. 133). Sin lugar a dudas, la dificultad de aprehensión de lo metodológico en el aprendizaje no es exigua y amenaza siempre el riesgo de abordajes tecnocráticos que mal entienden el método. Con todas estas dificultades, es posible presentar un acercamiento a su mínima descripción considerando cuestiones vinculadas a la división del trabajo, a las reglas y al instrumento mediador utilizado.

En principio, es importante señalar que los procesos de aprendizaje a los que nuestro análisis se aboca tienen lugar en una institución de enseñanza universitaria con una reglamentada estructura de división del trabajo: profesores, ayudante-alumnos y estudiantes. De manera que se establece un sistema típico de una institución de enseñanza de nivel superior que impide tanto el aislamiento de los procesos de aprendizajes como la omisión del conjunto de acciones dirigidas a la transmisión de conocimientos.

Al considerar esta situación, entendemos que desconocer la enseñanza en un sistema de actividad universitario en el que nos interesan los aprendizajes no tendría otros resultados más que la pérdida de la especificidad de los procesos mismos de aprendizaje. La razón por la que esto ocurre es que éstos se dan de una manera especial, justamente, porque son motorizados por decisiones sobre la enseñanza institucionalizada. Con ello nos referimos a decisiones sobre la creación de un "armazón estructural de un sistema interpsicológico" (Cole \& Engeström, 2001, p. 50) en el que el aprendizaje de la diagramación de argumentos se produce intencionalmente mediado por el uso de instrumentos y por la guía del docente.

En referencia a las reglas se toman, en particular, las que ordenan los principales sistemas de diagramación de argumentos. Entre ellos, uno de los métodos más tradicionales y poderosos para analizar pasajes argumentativos y exhibir diagramáticamente la estructura de los argumentos es el "arbóreo". Estrictamente, consiste en un sistema para la representación espacial de argumentos con forma ramificada que requiere la distribución de círculos para cada proposición y su unión con líneas para designar las relaciones inferenciales detectadas (Guevara, 2011).

Ahora bien: ¿cuáles son los instrumentos mediadores que tienen lugar en el aprendizaje de la diagramación de argumentos en el sistema analizado?

Si bien este sistema de diagramación ha sido históricamente practicado con tecnologías tradicionales -como por ejemplo con lápiz y papel y pizarras-, en la actualidad se encuentran numerosas aplicaciones de software que lo adoptan (Scheuer et al., 2010). Lo importante es destacar que, casi sin excepción, cada una de estas herramientas propone un procedimiento similar: el usuario debe introducir el argumento a analizar, diferenciar las premisas y la conclusión y trazar líneas que representen los lazos lógicos. 
Siguiendo esta misma operatoria, en el caso puntual del sistema de actividad que estudiamos, las Clases Prácticas de Lógica Informal se desarrollan alrededor del dominio de una extendida aplicación de software que adopta el sistema de representación de argumentos con estructura arbórea: Araucaria (Rowe, Macagno, Reed \& Walton, 2006).

\section{IV.Metodología}

El presente estudio tiene como objetivo describir y analizar la dinámica de constitución y desarrollo del sistema de actividad de diagramación de argumentos con el software Araucaria en clases universitarias de Lógica Informal (FFyH, UNC, Córdoba). Se aborda desde un estudio de caso, lo cual requiere localizar una "unidad individual" de análisis con fronteras claramente delimitadas $y$, al mismo tiempo, ponderar un tratamiento intenso y en profundidad que reconozca la importancia del contexto en el que se desarrolla y que le es constitutivo (Stake, 2010). Se espera, entonces, abarcar la complejidad del caso particular desde una perspectiva interpretativa o comprensiva en investigación (Tójar Hurtado, 2006) que, en ocasiones, integre exploraciones iniciales de tipo cuantitativo.

Además, es necesario mencionar que la inserción de la pregunta en la realidad de la casuística admite que los resultados a obtener presentan un potencial como posibilidad de teorización sobre cuestiones estructurales del fenómeno-objeto, y no como hallazgos que promueven la generalización empírica y la extensión estadística (Rockwell, 1987). En el mismo sentido, desde la perspectiva de Elias (1998), el caso posibilita observar en miniatura un escenario pequeño cuyas características especiales lo definen como un paradigma empírico que permite la reflexión más allá de sus propios límites. Así pues, señalamos la necesidad de detectar "configuraciones" que sean de interés para interpretar otros escenarios, más allá de la integración tecnológica en el campo específico de la Lógica Informal.

En virtud de este propósito, y durante un semestre, se observaron y registraron 11 clases de Trabajos Prácticos de las cuales 7 estuvieron dedicadas al uso de Araucaria para la diagramación argumental. De este conjunto de clases se obtuvo un corpus con exhaustivas transcripciones textuales de los intercambios verbales establecidos entre 13 estudiantes, 1 profesora y 1 ayudante alumno reunidos en una sala dotada de computadoras personales y un cañón proyector de imágenes.

La técnica de recolección de datos fue la observación no participante con grabación de audio y el instrumento diseñado contempló una guía que ayudó a configurar el cuaderno de campo. Durante este periodo de la investigación, se dedicó tiempo y trabajo intenso con el fin de lograr una descripción densa, rica y precisa no sólo de los elementos oídos sino también de los observados (gestos, movimientos, etc.) durante las sesiones de clase. Las transcripciones del audio fueron llevadas a cabo por los mismos investigadores luego de cada clase en virtud de reconstruir con la mayor fidelidad posible la experiencia del aula. Para el manejo preciso del corpus se identificaron y marcaron la totalidad de turnos de habla en las clases transcriptas según un sistema de codificación creado ad hoc (por ejemplo: "[G-T258]" indica el turno de habla 258 de la séptima clase $0 \mathrm{G}$ ).

Las técnicas de tratamiento y análisis de datos utilizadas fueron mixtas "cualitativascuantitativas". En un primer momento, se realizaron análisis cuantitativos exploratorios de frecuencias con un paquete estadístico $y$, posteriormente, análisis cualitativo de contenido 
semántico aplicando el principio de saturación conceptual para la generación de dimensiones y categorías pertinentes a ser profundizadas. En esta instancia de codificación y análisis de datos participaron dos investigadores para garantizar control recíproco y sistematicidad en el muestreo teórico realizado hasta el agotamiento de las categorías. Asimismo, se incluyó la supervisión de un experto en Lógica Informal con el objetivo de clarificar dudas y discusiones vinculadas al objeto de conocimiento trabajado en clases. Además de ello, la utilización de ambas estrategias (cualitativas y cuantitativas) requirió una rigurosa y precisa triangulación de datos que le otorgaron robustez al análisis. En términos operativos, para la demarcación de los numerosos fragmentos de enunciación y para la generación de categorías analíticas se utilizó el software de análisis cualitativo Weft QDA.

La adecuada inserción empírica y la vigilancia apropiada en el momento del análisis del material relevado contempló de manera transversal el "método funcional de la doble estimulación" (Vigotsky, 2009), es decir, la idea de incorporar instancias mediadoras "neutras" que, al explotar la función semiótica que recrean, transforman los modos de pensar sobre el objeto de aprendizaje. Luego, se trabajó con la distinción conceptual leontieviana "actividad - acción operación" para arrojar claridad en un contexto de prácticas que, pudimos reconocer, son abundantes y de diferentes tipos. Finalmente, desde Engeström recogimos la potencia analítica del trabajo alrededor de los principios que permiten analizar los sistemas de actividad. En especial, la noción de perturbaciones posibilitó captar la vitalidad de la escena y, con ello, el despliegue de discusiones sobre posibles trasformaciones sistémicas.

\section{Resultados}

Los resultados del estudio se pueden agrupar en tres ejes: "Patrón de intermitencia de prácticas y nuevas acciones"; "Manipulación diagramática por ensayo y error"; y "Perturbaciones sistémicas".

\section{a. Intermitencia de prácticas y "nuevas acciones"}

El rastreo inicial sobre el corpus establece que un locus de discusión es la intermitencia entre prácticas. Tal como se observa en el Gráfico 1, hemos marcado fragmentos correspondientes a tres categorías preliminares: a) "prácticas con computadora" manifiestas en los pasajes del registro en donde el sistema de actividad está orientado al trabajo operativo con las máquinas; b) "prácticas clásicas" para indicar el tipo de práctica que incluye, en su mayoría, a discusiones teóricas formuladas por los participantes respecto a la diagramación de argumentos; y c) "perturbaciones" entendidas como un tipo de práctica especial en el que se verbalizan contradicciones y tensiones sistémicas relativas al uso del software.

En principio, de allí surgen dos hallazgos generales: 1) no se observa interacción entre los circuitos de prácticas sino, 2) una cierta intermitencia de secciones que se activan de forma intercalada durante la progresión de cada clase. Preguntamos entonces, ¿qué hace dar el paso desde uno a otro circuito? 


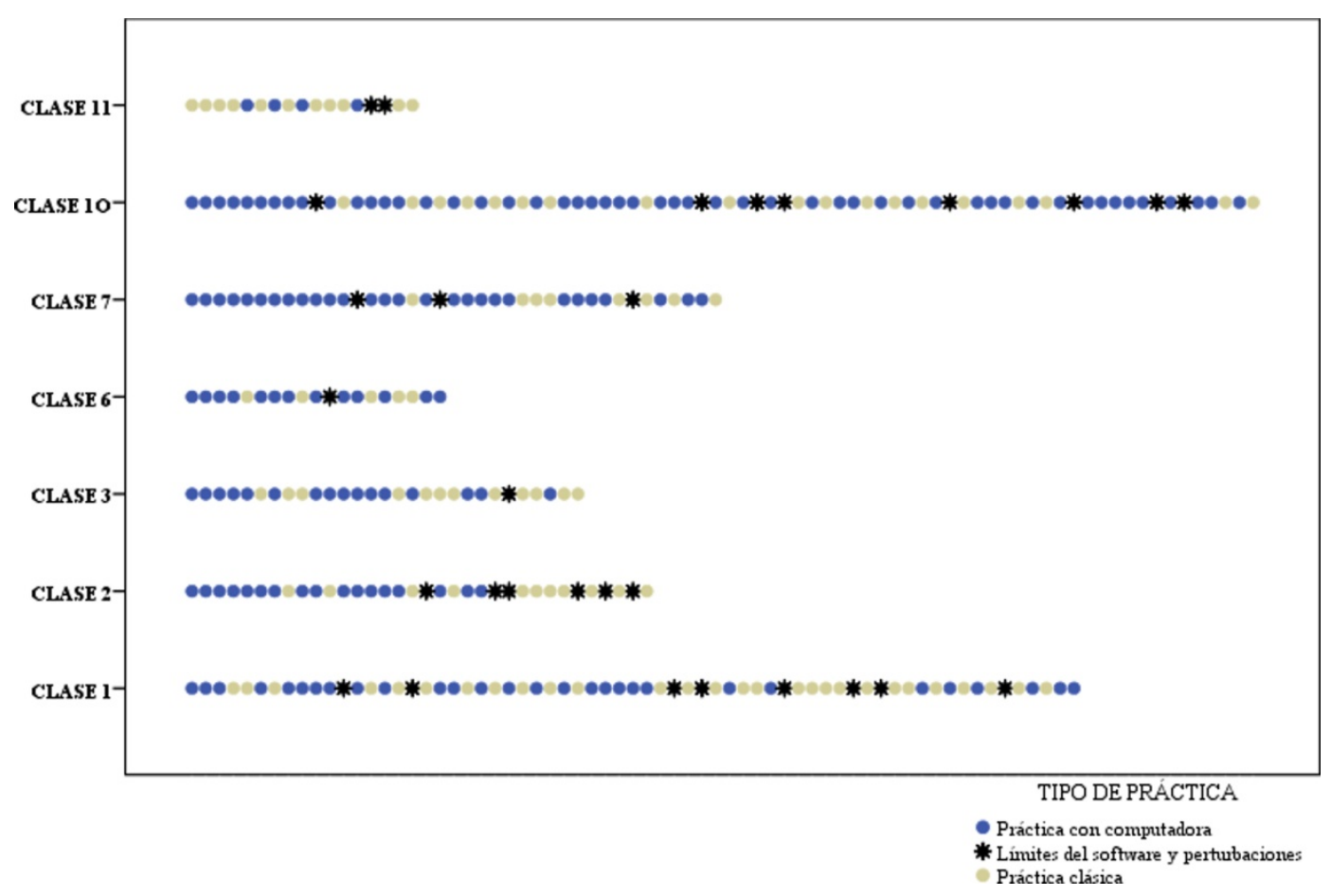

Gráfico 1. Intermitencia de prácticas en clases de Lógica Informal que usan Araucaria

Fuente: Elaboración propia de los autores.

La intermitencia entre prácticas denominadas "clásicas" y "con computadora" puede ser expresada en términos de ilustración de los contenidos disciplinares cuando se hace uso del software. En la fórmula "¿qué significa (el concepto X)? y ¿cómo se grafica?" se expresan tales "saltos" entre prácticas. No obstante, esta relación puede ser objeto de análisis más jugosos si es leída desde la distinción conceptual que establece Leontiev (1984) entre actividad, acción y operación.

En ese caso, se observa que el uso del software "agrega" un nuevo conjunto de acciones en la actividad, es decir, un nuevo conjunto de fines que determinan nuevas acciones y que aparecen toda vez que ocurren las presentaciones de los procedimientos generales para utilizar Araucaria (a saber: construir diagramas con formato arbóreo, diagramar tipos de argumentos, graficar argumentos según Toulmin y según el modelo dialógico).

Para ilustrar este hallazgo, y a modo de ejemplo, proponemos analizar un fragmento de la clase 1 en el que se presenta el procedimiento para diagramar argumentos con el formato arbóreo haciendo uso de Araucaria.

Considerando las categorías de Leontiev, entendemos allí como actividad a la diagramación de argumentos con forma de árbol. Si rastreamos los motivos, se observa que en frecuentes oportunidades, la docente expone las principales razones por las cuales la comunidad de lógicos y aprendices se ven motivados a diagramar argumentos. Por ejemplo, en diversos fragmentos del turno de habla 10 de la primera clase, la profesora hace referencia a que la diagramación es una "herramienta que permite identificar y visualizar la forma abstracta de un argumento $y$, de esta manera facilitar su análisis" puesto que "la idea que subyace a la representación diagramática es que la argumentación está caracterizada por estructuras que pueden 
describirse independientemente del contenido específico". Junto con ello, se establece que "la internalización de las estructuras argumentativas, contribuye en esta tarea de comprender y producir argumentos complejos" [A-T10].

Ahora bien, la distinción analítica en la que nos concentraremos para el análisis del fragmento expuesto en la Tabla 1 es la que existe entre acciones y operaciones. En primer lugar, señalamos que el procedimiento en cuestión se ejecuta según dos conjuntos distintos de acciones. Por un lado, acciones "clásicas" para la diagramación, es decir aquellas realizadas tradicionalmente sin intervención de software. Por el otro, acciones que corresponden a la diagramación con Araucaria junto con el agregado de operaciones que establecen directamente las condiciones necesarias para su consecución.

\begin{tabular}{|c|c|c|c|}
\hline $\mathbf{N}^{\circ}$ & $\begin{array}{l}\text { Acciones } \\
\text { "clásicas" para } \\
\text { diagramación }\end{array}$ & $\begin{array}{l}\text { Acciones para } \\
\text { diagramación con } \\
\text { Araucaria }\end{array}$ & Operación \\
\hline 1 & - & $\begin{array}{l}\text { Cargar archivos. } \\
\text { [A-T28] }\end{array}$ & $\begin{array}{l}\text { Seleccionar Open text file, luego buscar } \\
\text { el nombre del archivo .txt y clic en abrir. } \\
\text { [A-T28] }\end{array}$ \\
\hline 2 & $\begin{array}{l}\text { Leer argumento. } \\
\text { [A-T30] }\end{array}$ & - & - \\
\hline 3 & $\begin{array}{l}\text { Identificar } \\
\text { proposiciones. } \\
\text { [A-T32] }\end{array}$ & - & - \\
\hline 4 & - & $\begin{array}{l}\text { Marcar proposiciones. } \\
\text { [A-T34] }\end{array}$ & $\begin{array}{l}\text { Marcar cada proposición con el mouse } \\
\text { sostenido. Clic en pantalla blanca para } \\
\text { que aparezca nodos en barra inferior. [A- } \\
\text { T34] }\end{array}$ \\
\hline 5 & - & $\begin{array}{l}\text { Subir nodos } a \\
\text { interfaz blanca. [A- } \\
\text { T38] }\end{array}$ & $\begin{array}{l}\text { Clic sostenido desde un nodo a otro para } \\
\text { que aparezcan en interfaz blanca. [A- } \\
\text { T38] }\end{array}$ \\
\hline 6 & - & $\begin{array}{l}\text { Borrar flechas. } \\
\text { [A-T41] }\end{array}$ & $\begin{array}{l}\text { Seleccionar las flechas y clic en ícono de } \\
\text { delete. }[\mathbf{A}-\mathbf{T 4 1}]\end{array}$ \\
\hline 7 & $\begin{array}{l}\text { Identificar } \\
\text { relaciones } \\
\text { inferenciales. } \\
\text { [A-T43]; [A-T49] }\end{array}$ & - & - \\
\hline 8 & - & $\begin{array}{l}\text { Marcar relaciones } \\
\text { inferenciales. [A- } \\
\text { T47] }\end{array}$ & $\begin{array}{l}\text { Clic sostenido desde el nodo premisa al } \\
\text { nodo conclusión. [A-T47] }\end{array}$ \\
\hline 9 & - & $\begin{array}{l}\text { Guardar diagrama. } \\
\text { [A-T49] }\end{array}$ & $\begin{array}{l}\text { Clic en File, luego en Save as. Escribir el } \\
\text { nombre y clic en aceptar. [A-T49] }\end{array}$ \\
\hline
\end{tabular}

Tabla 1. Secuencia y procedimiento general de la actividad: diagramación de árboles

Fuente: Elaboración propia de los autores. 
Si analizamos la Tabla 1 en detalle, primero se presenta una acción en el software (cargar archivos) y luego su operación correspondiente. Sobreviene una acción clásica, la de leer el argumento a diagramar. Consecuentemente es necesario continuar con el protocolo clásico: identificar proposiciones. Una vez realizada esta acción, se marcan las proposiciones, se suben los nodos a la interfaz blanca y se borran las flechas mal dispuestas. Estas tres últimas acciones para diagramar con Araucaria son logradas por una serie de comandos que constituyen sus propias operaciones. Continuando con la secuencia, sobreviene la acción clásica de identificar relaciones inferenciales, acción que no tiene un correlato como acción en Araucaria y por lo tanto carece de operación. Ello es sugerente de la escasez de medios o condiciones que el software ofrece para llevar a cabo la totalidad de las acciones. Finalmente, la profesora y los estudiantes marcan las relaciones inferenciales en la interfaz y guardan el diagrama. Se trata de acciones de diagramación típicas del trabajo con el software y de sus operaciones correspondientes.

Conforme esta descripción, ratificamos que el patrón de relación es la intermitencia de acciones. Por un lado, hallamos que las acciones clásicas no son "operacionalizadas" por acciones con Araucaria. Recíprocamente y, por el otro lado, advertimos la existencia de acciones llevadas adelante con el software -típicamente prácticas- que no traducen ninguna acción clásica y que naturalmente se consiguen haciendo caso de operaciones específicas que tienen la forma de listas de comandos. Debe señalarse, además, que este patrón no es aislado: la reconstrucción de los otros fragmentos en donde se abordan los demás procedimientos generales para la diagramación, corrobora los resultados observados en el primer caso.

Es necesario, entonces, no perder de vista la existencia de acciones clásicas que son previas y que no pueden realizarse con Araucaria. Alrededor de estas acciones independientes del software es que, como mostraremos luego, los estudiantes realizan reclamos por automatización en instancias de clara perturbación sistémica.

Ahora bien, si avanzamos en la progresión típica de cada clase analizada, podemos retomar la instancia en que, una vez presentados los procedimientos generales, los estudiantes comienzan a diagramar utilizando los comandos y operaciones para resolver los ejercicios planteados. En este momento, observamos las demandas de los alumnos para recordar las instrucciones a ingresar en el software y los problemas asociados al control técnico de la herramienta. Se trata de una instancia de predominante "aprestamiento" en el uso del software: un proceso inmediatamente anterior al despliegue total del sistema de actividad de diagramación tal como lo establece la comunidad de expertos.

En resumen, el análisis realizado nos permite puntualizar que: a) las acciones para la diagramación con Araucaria se constituyen en un nuevo conjunto de acciones que se "agregan" en el sistema de actividad y que, al estar definidas por su calidad técnica, en la práctica tradicional no existen; y b) el entrenamiento de este nuevo conjunto de acciones supone un "aprestamiento técnico" cada vez que se incorporan nuevas unidades temáticas expresadas en nuevos procedimientos con el software.

A raíz de estos señalamientos, en esta instancia de la evolución sistémica observamos un movimiento de "repliegue" del instrumento mediador (software) sobre la posición del objeto. Esta tendencia es frecuente en prácticas típicas del formato escolar moderno al producirse movimientos en los que el manejo de ciertas herramientas se convierte en el objetivo perseguido de la enseñanza. Así, los instrumentos resignan su carácter mediador en el proceso y al menos, por un tiempo, toman lugar de objeto de aprendizaje en sí mismos. Para nosotros esta será la primera concreción del sistema de actividad: la de su repliegue. 


\section{b. Manipulación diagramática: ensayo y error}

Posteriormente a las instancias de repliegue, cuando ya no quedan dudas respecto de los comandos a ingresar para lograr las operaciones requeridas, ocurre el "despliegue" del sistema de actividad. Esto significa que el software vuelve a tomar su lugar de instrumento mediador y el objeto de la actividad coincide, ahora, con el sistema en su definición según las prácticas del experto/docente. De este modo, el motivo de la actividad vuelve a ser el aprendizaje de la diagramación de argumentos y ya no la instrucción técnica en el manejo del software.

En esta segunda concreción del sistema de actividad, el uso de Araucaria añade un conjunto de posibilidades de acción vinculadas con el ensayo, error, deshecho y prueba de nuevas alternativas diagramáticas. En ese punto el software se establece para los estudiantes como una herramienta que facilita la manipulación de la información.

\begin{tabular}{|c|c|}
\hline Fragmento de clase & Acción \\
\hline $\begin{array}{l}\text { [A-T40] ALUMNA: Con la flecha nos salió. } \\
\text { [A-T41] PROFESORA: Sí, bueno, marquen las flechas y apliquen este que } \\
\text { es el delete. }\end{array}$ & Borrar flechas \\
\hline $\begin{array}{l}\text { [C-T1] ALUMNO: [Explicándole a otro compañero sobre el funcionamiento } \\
\text { del software]. (...) Entonces para desarmar eso, te paras ahí arriba, así se } \\
\text { selecciona y con eso borras. Ahí están al lado, y después los re-ordenás } \\
\text { como te parece (...). }\end{array}$ & $\begin{array}{l}\text { Reacomodar } \\
\text { nodos }\end{array}$ \\
\hline $\begin{array}{l}\text { [G-T257] ALUMNA: Ya llevo como F y me falta la mitad del argumento. } \\
\text { [G-T258] ALUMNA: Y después hay que reordenarlos... }\end{array}$ & Reordenar nodos \\
\hline $\begin{array}{l}\text { [G-T284] PROFESORA: Bueno vamos a undo (risas). } \\
\text { [G-T285] ALUMNA: El famoso undo (risas pícaras). }\end{array}$ & $\begin{array}{l}\text { Deshacer } \\
\text { diagrama }\end{array}$ \\
\hline $\begin{array}{l}\text { [J-T62] PROFESORA: Bien. Pero en realidad "Se ha observado que todas las } \\
\text { hermanas de Jack son pelirrojas" es... } \\
\text { [J-T63] ALUMNA: Es respaldo... } \\
\text { [J-T64] PROFESORA: iMuy bien! Muy bien, entonces, a ver si se les puede } \\
\text { cambiar... Fíjense que, para cambiar, lo podés convertir en refutación o en } \\
\text { dato (...). }\end{array}$ & $\begin{array}{l}\text { Convertir tipo de } \\
\text { nodo }\end{array}$ \\
\hline $\begin{array}{l}\text { [J-T142] ALUMNA: ¿Borro todo? } \\
\text { [J-T143] PROFESORA: No, no, en realidad borrale las flechitas, que te } \\
\text { queden las cajas sin las flechas. }\end{array}$ & $\begin{array}{l}\text { Borrar flechas } y \\
\text { reacomodar nodos }\end{array}$ \\
\hline $\begin{array}{l}\text { [K-T78] ALUMNA: Claro... ¿Cómo hacés para borrar? } \\
\text { [K-T79] PROFESORA: Con la flechita del deshacer. }\end{array}$ & Deshacer \\
\hline
\end{tabular}

Tabla 2. Ejemplos de manipulación y prácticas de ensayo y error

Fuente: Elaboración propia de los autores. 
Los fragmentos ejemplificadores de la Tabla 2 ponen en evidencia el uso activo que se hace de la herramienta durante todo el semestre para borrar relaciones inferenciales erróneas, reacomodar y reordenar cajas, deshacer diagramas y convertir tipos de nodos. Alusiones a estos "beneficios" del software aparecen en reiteradas ocasiones del corpus analizado y permiten indicar que la diagramación se muestra como una práctica distendida, una actividad que contempla la prueba de posibilidades de visualización de la estructura argumental.

Esta repetición de los movimientos con el software también ha sido advertida por LantzAndersson, Linderoth y Säljö (2009) pero con herramientas que propinaban un feedback a las respuestas de estudiantes adolescentes para ejercicios de matemática. En ese caso, cuando el programa devolvía el ejercicio como incorrectamente resuelto, el método iterativo empleado por los estudiantes suponía ingresar nuevas respuestas repetidamente y sin esfuerzo analítico. A raíz de ello, los autores señalaban que "los estudiantes parecían dejar de lado el marco de referencia matemático $y$, en su lugar, decidían operar según el marco establecido por el software hasta alcanzar la respuesta correcta" (Lantz-Andersson et al., 2009, p. 431).

En contraste, nuestros resultados indican que las estrategias repetitivas de uso del software no incluyen una iteración "descontrolada" a la espera de feedback positivo. Como Araucaria no proporciona evaluaciones automatizadas, la repetición de prácticas sigue respondiendo al marco lógico disciplinar. Esto nos permite sugerir que la connotación especial que toman tales estrategias iterativas depende del diseño de los programas en lo que respecta a su dimensión evaluativa.

El punto aquí es que el sentido de iteración que encontramos se vincula con la practicidad en la manipulación de la información. Conforme con este hallazgo, existen pasajes en nuestro material de análisis donde se propone imaginar los límites del ensayo diagramático con otras tecnologías para rescatar, así, la utilidad del uso de Araucaria [B-T67]. Se entiende que, ante tales situaciones, es claro que Araucaria aporta practicidad y es por ello que, al incorporarlo, el sistema de actividad se beneficia sobre todo cuando se diagraman argumentos extensos y de estructura compleja [F-T145].

No obstante, estos beneficios entendidos en términos de una cierta practicidad en el manejo de los diagramas no disuelven la crítica al reduccionismo informativo cuando se incorpora software en educación (Burbules \& Callister, 2008). Claramente, los datos expuestos hasta aquí no nos permiten hablar de formas concretas de renovación de las prácticas de diagramación. Es decir que no se advierten prácticas innovadoras que sólo pueden alcanzarse con la intervención de nuevas tecnologías en las clases.

De todas maneras, lo importante aquí es la descripción profunda de este conjunto de posibilidades vinculadas con maniobras sobre los componentes de los diagramas. Si consideramos las conceptualizaciones de Twining (2002) es posible observar que la manipulación eficiente de los diagramas corresponde a manifestaciones del modo "soporte". Éste estipula que al utilizar el software, el contenido a aprender no se transforma (aunque se adosan otros objetivos de aprendizaje vinculados con el antes mencionado "aprestamiento técnico"), y que, si bien el proceso de aprendizaje se automatiza, en su esencia no es cambiado. En suma, se hace más eficiente la práctica sin transformar ni el contenido ni los procesos de aprendizaje.

Esto significa que las prácticas de manipulación diagramáticas exponen formas de acción con el software que, si bien no producen transformaciones estructurales en el sistema de actividad, aportan algunos beneficios prácticos no reductibles a una iteración irreflexiva. Lo interesante es que el objeto de la actividad no es transformado y que tampoco los motivos del sostenimiento del sistema se modifican. 


\section{c. Perturbaciones sistémicas}

El análisis de las interacciones entre los estudiantes y Araucaria pone de manifiesto algunas "acciones imposibles" de repetición típica durante las clases. Se trata de las referencias explícitas que realizan los sujetos sobre los límites del diseño del software y sobre lo que conceptualizamos como "perturbaciones" en el sistema de actividad de diagramación.

Según se ha mostrado en el gráfico de barras apilado (ver Gráfico 1), se detectan límites y perturbaciones en 29 ocasiones durante las clases sometidas a análisis. Es decir, instancias donde acaecen desviaciones respecto del guión prescripto por la práctica consagrada (Engeström, 2001a) a partir de las cuales observamos persistentes demandas de automatización en la resolución de los ejercicios diagramáticos. Esto significa que los alumnos esperan que Araucaria les provea una evaluación de la actividad diagramática realizada o que, en su defecto, les sugiera claves para resolver los ejercicios. En otras palabras, la respuesta "esperada" apunta a automatizar el agrupamiento de acciones que no pueden realizarse con Araucaria (lo que previamente deslindamos como el conjunto de "acciones clásicas" para la diagramación argumental). Ocurre que, ante la incapacidad de la herramienta para dar respuesta a estas demandas, la justificación del uso del software se debilita y emerge una especie de "sin sentido" de la práctica.

Tal como puede observarse en la Tabla 3, en ocasión del tratamiento de cada nuevo núcleo temático, aparece la demanda irresuelta. Para la diagramación de árboles los estudiantes esperan que el programa identifique los pasos inferenciales (ver en Tabla 3 el fragmento 1) o que evalúe el diagrama ingresado (fragmento 2). En la diagramación de tipos de argumentos, los estudiantes no parecen satisfechos con las marcas gráficas con las que el software diferencia las estructuras argumentales (fragmento 3) y menos con la respuesta obtenida ante su expectativa de que la herramienta identifique automáticamente entre la tipología (fragmento 4). La diagramación de argumentos según el modelo de Toulmin muestra también la demanda insatisfecha de resolución automática del diagrama (fragmento 5). Finalmente, la diagramación argumental de carácter dialógico encuentra que el output es sólo un marcado gráfico sobre los argumentos de cada parte que están involucradas en la disputa (fragmento 6).

\begin{tabular}{|c|l|l|}
\hline $\mathbf{N}^{\circ}$ & \multicolumn{1}{|c|}{ Fragmentos de clase ejemplificadores } & Núcleo temático \\
\hline 1 & $\begin{array}{l}\text { [A-T43] PROFESORA: Porque la flecha va desde la premisa hasta la } \\
\text { conclusión, entonces, la idea es que ahora veamos eso para ver a } \\
\text { dónde va la flecha, si es que estaba bien o no... bueno ¿qué les } \\
\text { parece? (risas) ¿Cuál es la premisa y cuál la conclusión? (risas). } \\
\text { Claro ieso ya no lo hace el programa! Es para diagramar nada } \\
\text { más... }\end{array}$ & $\begin{array}{l}\text { Diagramación de } \\
\text { árboles. }\end{array}$ \\
\hline 2 & $\begin{array}{l}\text { [B-T49] ALUMNA: El programa no te dice si está bien o está mal. } \\
\text { Eso es un defecto. }\end{array}$ & $\begin{array}{l}\text { Diagramación } \\
\text { árboles. }\end{array}$ \\
\hline 3 & $\begin{array}{l}\text { [G-T117] ALUMNA: iAh! ¿te pone el título nomás? } \\
\text { [G-T118] PROFESORA: Claro, te etiqueta el tipo de argumento que } \\
\text { es. (risas). }\end{array}$ & $\begin{array}{l}\text { Diagramación de tipos } \\
\text { de argumentos. }\end{array}$ \\
\hline 4 & $\begin{array}{l}\text { ¿G-T88] PROFESORA: Y de ahí vas de nuevo al esquema, Select, de argumento es? (El alumno la mira y se ríe). iEso lo lo } \\
\text { tenés que pensar vos! (risas). ¿Qué tipo de argumento es?... }\end{array}$ & $\begin{array}{l}\text { Diagramación de tipos } \\
\text { de argumentos. }\end{array}$ \\
\hline
\end{tabular}




\begin{tabular}{|c|c|c|}
\hline 5 & $\begin{array}{l}\text { [J-T54] PROFESORA: Ah, sí, claro... no se hace solo... Esto sigue } \\
\text { siendo igual, por más que... Por más que estén en Toulmin... } \\
\text { [J-T55] ALUMNA: iOh! Pensé que Toulmin nos hacía el trabajo (...). }\end{array}$ & $\begin{array}{l}\text { Diagramación según } \\
\text { modelo de Toulmin. }\end{array}$ \\
\hline 6 & $\begin{array}{l}\text { [J-T388] ALUMNA: Y en el otro, en el cuadradito que dice "esto es } \\
\text { ridículo viniendo de usted"... (la profesora asiente). Claro, es } \\
\text { solamente eso... } \\
\text { [J-T389] PROFESORA: Sí... no, no, no era tan... (risas). } \\
\text { [J-T390] ALUMNA: Pero no hay cómo... } \\
\text { [J-T391] ALUMNO: Cómo hacerlos pelear (risas). } \\
\text { [J-T392] ALUMNA: iClaro! Yo quiero que se peleen. } \\
\text { [J-T393] PROFESORA: Y no, porque los dos llegan a conclusiones } \\
\text { diferentes. No van a llegar a lo mismo. } \\
\text { [J-T394] ALUMNA: Malísimo. }\end{array}$ & $\begin{array}{l}\text { Diagramación según } \\
\text { modelo dialógico. }\end{array}$ \\
\hline
\end{tabular}

Tabla 3. Perturbaciones por demandas de resolución automática

Fuente: Elaboración propia de los autores.

Debido a las perturbaciones que resultan de las demandas de resolución insatisfechas se advierte, en ciertas oportunidades, que los estudiantes proponen la intercambiabilidad de la tecnología como reflexión general ante las limitaciones que establece el uso del software. Dicen al respecto: "Es mejor cuando tenés una hoja..." [B-T61]; "Si tuviéramos lápiz y papel nada de esto estuviera pasando..." [J-T192]; "Nada que con una buena hoja..." [J-T398].

A la luz de estos dichos recogidos en distintas instancias del semestre, la opción del lápiz y papel parece ofrecer beneficios tan o más potentes como los proporcionados por Araucaria. Incluso, es pertinente aquí considerar un suceso ocurrido durante la cuarta clase en la que un estudiante propuso la entrega de un trabajo práctico domiciliar de diagramación utilizando un procesador de texto: "(...) Los hice en Word a los ejercicios, ite los puedo entregar así?" [D-T56].

El hecho es relevante en este contexto -aunque el problema subyacente era técnico- puesto que para el estudiante era perfectamente concebible optar por otra herramienta digital que reemplace al software recomendado y que le permita la construcción de los diagramas argumentales. Surge entonces la pregunta por la intercambiabilidad tecnológica: ¿da lo mismo diagramar argumentos con Araucaria, con lápiz y papel o con un procesador de textos de uso habitual? Evidentemente, las expectativas insatisfechas al usar el software -sobre todo expectativas de producción y evaluación automática de los argumentos- parecen diluir desde el punto de vista de los estudiantes la existencia de "beneficios exclusivos" de Araucaria. Todas estas discusiones se disparan al considerar la tercera concreción del sistema de actividad: la de las perturbaciones.

\section{Discusión y conclusiones}

Los principales resultados indican la existencia tanto de acciones posibles con el programa informático, como de otras cuya consecución estuvo limitada. Entre las primeras se encuentran 
acciones vinculadas al aprestamiento técnico y a la capacidad práctica de manipulación informacional y prueba. No obstante, otras acciones analizadas revelan la insuficiencia del diseño del software para transformar el contenido del aprendizaje y, por lo tanto, para modificar las prácticas tradicionales de diagramación de argumentos. Es claro que las perturbaciones representadas por estas imposibilidades sistémicas, abren paso para realizar análisis sobre los ciclos de transformaciones posibles.

Veamos finalmente con más detenimiento la dinámica de evolución del sistema de actividad estudiado (Figura 2).
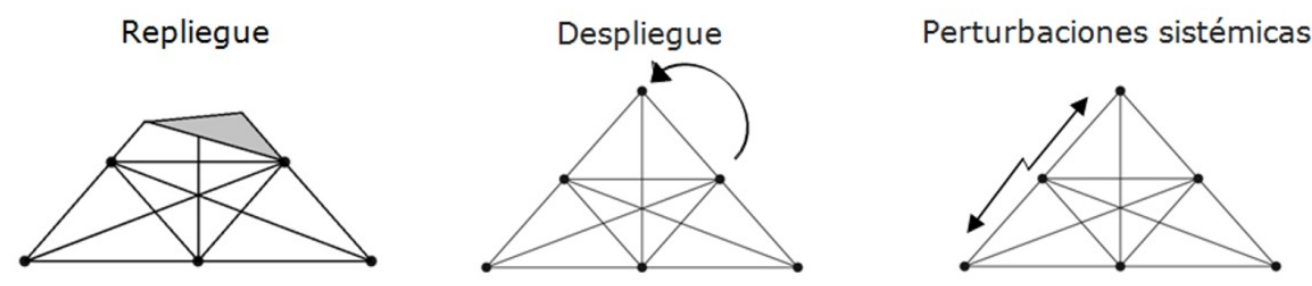

Figura 2. Concreciones del sistema de actividad para la diagramación con Araucaria

Fuente: Elaboración propia de los autores a partir de Engeström (2015).

Al analizar las relaciones entre prácticas clásicas y con computadora hemos descrito vínculos de ilustración de lo teórico por lo práctico y la discontinuidad provocada por el agregado de un nuevo conjunto de acciones típicamente técnicas y sólo necesarias a los fines de hacer funcionar el software. En estas circunstancias, identificamos la primera concreción del sistema de actividad según ocurre el repliegue del instrumento mediador en la posición del objeto de aprendizaje.

Esta dinámica tiene efectos importantes en el sistema. Por un lado, el movimiento de repliegue hace perder el carácter mediador del instrumento y lo instala como un fin en sí mismo. Ello se conoce como "descontextualización" del instrumento y suele ser muy frecuente en los sistemas formales de educación. Por otro lado y al mismo tiempo, Araucaria se presenta como una herramienta que, al ocupar el lugar de objeto en el sistema de actividad, termina por desconocer las motivaciones iniciales de su utilización en esa situación. A saber: el uso planificado en términos de motivación del sistema no coincide con el que efectivamente se encuentra en esta instancia. De manera que aquí, los motivos "consagrados" de la actividad -aquellos por los que se entiende que la diagramación argumental permite capturar la "forma" o "estructura" subyacente de un argumento- son trocados por motivos en los que el aprestamiento técnico ocupa un lugar predominante. En otras palabras: la motivación para diagramar argumentos se suspende y la actividad se define por un nuevo motivo vinculado al manejo técnico del programa informático.

Alrededor de esta reconfiguración de los motivos, se produce el agregado de un nuevo conjunto de acciones independientes de las motivaciones que fundan el sistema de actividad y que se reducen a una educación técnica del manejo operativo del software. Este hallazgo coincide con las descripciones realizadas por Lantz-Andersson (2009) respecto del establecimiento de un nuevo marco de referencia que adiciona complejidad e introduce nuevas dimensiones al sistema cuando se incorporan herramientas digitales.

A este respecto, mucho suele decirse en torno a las innovaciones casi automáticas que suministrarían los softwares educativos. No obstante, la evidencia empírica muestra que, en 
contra de cierta ilusión mágica de eficacia, incorporar nuevas tecnologías requiere, necesariamente, sumar nuevos objetos con reglas de uso específicas e independientes de las prácticas tradicionales de aprendizaje. Tanto que, en ocasiones, el sistema de actividad en su conjunto se ve redefinido al modificarse el motivo de su existencia.

El segundo momento de concreción del sistema de actividad rescata un conjunto de posibilidades de acción con Araucaria. Se trata de la capacidad de manipulación y prueba que hace posible un aumento de la eficiencia sin llegar a reducir esta posibilidad a una iteración irreflexiva cuando se construyen diagramas. De modo que se reconquista la motivación de la actividad diagramática y se desdibuja el anterior interés por el dominio de la operatoria del software y sus comandos. Denominamos a esta instancia según ocurre el despliegue de las posiciones de la unidad de análisis, es decir, la vuelta de la herramienta a una posición mediadora.

No obstante, si bien los motivos vuelven a definir el sistema de actividad en términos de diagramación de argumentos, esta actividad no se distingue claramente de los modos tradicionales con los que ha sido llevada a cabo en la disciplina. Sostendremos que, a pesar del uso de Araucaria, no se observa una transformación de las prácticas clásicas de diagramación de argumentos. Esto quiere decir que, si bien hemos mostrado el aumento de la eficiencia en la manipulación de información, aún no se identifican prácticas en las que el uso de Araucaria resulte imprescindible para llevar adelante la actividad.

Tal dificultad para dar cauce a la innovación responde, desde nuestra perspectiva, a un problema de diseño del software por cuanto se reproducen los contenidos y los motivos tradicionales que definen a la diagramación de argumentos como sistema de actividad. Como bien ha sido documentado en otras investigaciones (Area Moreira, 2009; de Pablos Pons, 2009; Dussel \& Quevedo, 2010; Gewerc, 2010; Litwin, 2005; Sancho Gil, 2006), nuestros hallazgos muestran que la mera incorporación tecnológica no es suficiente para transformar las prácticas y que, por el contrario, a veces, hasta añade inconvenientes.

Finalmente, el tercer momento de concreción del sistema de actividad contempla las contradicciones observadas cuando se analizan las intervenciones de los estudiantes. Se trata de perturbaciones en torno a la demanda de resolución automática que, claramente, no es satisfecha por la herramienta cada vez que se trabaja un nuevo contenido diagramático.

Al analizar la unidad de análisis, la expresión de contradicciones sistémicas tiene lugar en la línea que vincula al instrumento mediador, los sujetos que lo utilizan y las reglas que fija el mismo software (especialmente en términos de sistema diagramático). Preguntamos allí si el hecho de que Araucaria no incorpora transformaciones significativas para la actividad en comparación con tecnologías tradicionales (lápiz y papel), constituye la explicación que permite entender el carácter obsoleto que los estudiantes le adjudican a la herramienta. A saber: el sistema de actividad de la diagramación puede resolver su puesta en marcha sin la necesidad de incluir nuevas tecnologías del tipo de Araucaria, razón por la cual se fundamenta su reemplazo o intercambio.

En concreto, creemos que las perturbaciones detectadas se establecen alrededor del traslado de un sistema de diagramación clásico (arbóreo) a un entorno virtual en el que no se produce la transformación de los contenidos. Esto significa que los estudiantes observan un traspaso más o menos reproductivo de un lenguaje de diagramación diseñado previamente a un entorno virtual.

La hipótesis de trabajo futuro supone que en el caso del sistema de actividad de diagramación argumental, más allá de la tecnología material (entiéndase aplicaciones de software específicas), interesan las distinciones entre diferentes sistemas de diagramación de argumentos. De esta 
manera, se relocaliza la importancia del lenguaje diagramático o del "instrumento psicológico" en su profundo sentido vigotskyano. A este respecto, es oportuno destacar la precaución a la que alude Bustamante Smolka (2010). La autora denuncia estudios que "sobrevalorizan" las similitudes entre signo e instrumento (material) dejando de lado el hecho de que la analogía vigotskyana es el camino heurístico tomado para llegar a localizar la importancia del signo y el lenguaje, para valorar sus diferencias con las herramientas materiales, para ensalzar, en definitiva, el interés semiótico de su psicología.

Tal corrimiento de la indagación reclama, finalmente, avanzar sobre las posibilidades de transformación sistémica. Si, como antes hemos considerado, los sistemas de actividad son transformados cuando hay cambios en su objeto y su motivo, será necesario, consecuentemente, idear la innovación sobre estas dos dimensiones. En nuestro caso, ello supondrá probar otro sistema (lenguaje) de diagramación de argumentos aunque no cualquiera de ellos: un sistema de diagramación que eche mano y utilice recursos típicos y distintivos de las tecnologías digitales con las que contamos actualmente.

Con todo, es necesario señalar que aún queda pendiente el análisis de prácticas en Lógica Informal que utilizan aplicaciones de software de aparición todavía más reciente; por ejemplo, aquellas experiencias y herramientas que integran trabajo colaborativo online con el propósito de diagramar argumentos en proyectos más ambiciosos que involucran a muchos más participantes. Estos casos también podrían ser evaluados en términos de innovación educativa dando cuenta de rasgos típicos y nuevas formas de argumentar en internet. Para ello, la probada potencia teórica del Enfoque Sociocultural se presenta como una perspectiva apropiada en vistas a reconstruir con el mayor refinamiento posible los modos con los que se produce o no la emergencia de usos innovadores e interesantes en contextos de aprendizaje con nuevas tecnologías.

Sobre todo, creemos importante destacar que las concreciones del sistema de actividad aquí identificadas pueden considerarse recursos heurísticos adecuados a la hora de analizar otros escenarios en los que se usan aplicaciones de software para la enseñanza en instituciones educativas. Más allá de las especificidades del caso del aprendizaje de la diagramación de argumentos en Lógica Informal; las fases de repliegue del instrumento mediador, su despliegue y las perturbaciones sistémicas estudiadas pueden constituirse en organizadores analíticos de otras experiencias en las que se investigue la emergencia de prácticas novedosas, es decir, la posibilidad de transformaciones tanto del objeto como del motivo del sistema desplegado. En base a ello, la selección de software para la enseñanza de diferentes disciplinas puede también verse afectada por análisis de este tipo puesto que, claramente, está enfocado en las posibilidades de mejorar las prácticas áulicas.

\section{Referencias}

Burbules, N. \& Callister, T. (2008). Educación: riesgos y promesas de las nuevas tecnologías de la información. Buenos Aires: Ediciones Granica.

Bustamante Smolka, A. L. (2010). Lo (im)propio y lo (im)pertinente en la apropiación de las prácticas sociales. En N. Elichiry (Comp.), Aprendizaje y contexto: contribuciones para un debate (pp. 41-59). Buenos Aires: Manantial.

Chaiklin, S. \& Lave, J. (Comp.). (2001). Estudiar las prácticas. Perspectivas sobre actividad y contexto. Buenos Aires: Amorrortu.

Cole, M. \& Engeström, Y. (2001). Enfoque histórico-cultural de la cognición distribuida. En G. Salomon (Comp.), Cogniciones distribuidas. Consideraciones psicológicas y educativas (pp. 23-74). Buenos 
Aires: Amorrortu.

Coll, C. \& Monereo, C. (Eds.). (2008). Psicología de la educación virtual. Aprender y enseñar con las Tecnologías de las Información y la Comunicación. Madrid: Morata.

Coll, C. (2004). Psicología de la educación y prácticas educativas mediadas por las tecnologías de la información y la comunicación. Una mirada constructivista. Revista Electrónica Sinéctica, 25, 1-24. Recuperado en: http://www.redalyc.org/articulo.oa?id=99815899016

Coll, C., Mauri, T. \& Onrubia, J. (2008). Análisis de los usos reales de las TIC en contextos educativos formales: una aproximación sociocultural. Revista Electrónica de Investigación Educativa, 10(1), 118. Recuperado en: http://www.redalyc.org/articulo.oa?id=15510101

Coll, C., Onrubia, J. \& Mauri, T. (2007). Tecnología y prácticas pedagógicas: las TIC como instrumentos de mediación de la actividad conjunta de profesores y estudiantes. Anuario de Psicología 2007, 38(3), 377-400. Recuperado en: http://revistes.ub.edu/index.php/Anuariopsicologia/article/viewFile/8407/10382

Cuban, L. (2001). Oversold and underused. Computers in the classroom. Estados Unidos: Harvard University Press.

Davies, M. \& Barnett, R. (2015). The Palgrave Handbook of Critical Thinking in Higher Education. New York, NY, USA: Palgrave.

De Pablos Pons, J. (Coord.) (2009), Tecnología educativa. La formación del profesorado en la era de Internet. Archidona: Aljibe.

Dunn, D.S., Halonen, J.S. \& Smith, R.A. (2008). Teaching critical thinking in psychology. A handbook of best practice. Chichester: Wiley-Blackwell.

Dussel, I. \& Quevedo, L. A. (2010). VI Foro Latinoamericano de Educación: Educación y nuevas tecnologías: los desafíos pedagógicos ante el mundo digital. Buenos Aires: Santillana.

Dussel, I. \& Trujillo Reyes, B. F. (2018). ¿Nuevas formas de enseñar y aprender? Las posibilidades en conflicto de las tecnologías digitales en la escuela. Perfiles Educativos, Número especial XL, 1-37. Recuperado en: http://www.iisue.unam.mx/perfiles/articulo/2018-e-nuevas-formas-de-ensenar-yaprender-las-posibilidades-en-conflicto-de-las-tecnologias-digitales-en-la-escuela.pdf

Elias, N. (1998). La civilización de los padres y otros ensayos. Buenos Aires: Grupo Editorial Norma.

Engeström, Y. (2000). Activity Theory as a framework for analyzing and redesigning work. Ergonomics, 43(7), 960-974. doi: 10.1080/001401300409143

Engeström, Y. $\left(2001^{\mathrm{a}}\right)$. Expansive learning at work: toward an activity theoretical reconceptualization. Journal of Education and Work, 14(1), 133-156. Recuperado en: http://www.tandfonline.com/doi/pdf/10.1080/13639080020028747

Engeström, Y. $\left(2001^{\mathrm{b}}\right)$. Los estudios evolutivos del trabajo como punto de referencia de la teoría de la actividad: el caso de la práctica médica de la asistencia básica. En S. Chaiklin y J. Lave (Comp.), Estudiar las prácticas. Perspectivas sobre actividad y contexto (pp.78-118). Buenos Aires: Amorrortu.

Engeström, Y. (2015) [1987]. Learning by expanding: An activity-theoretical approach to developmental research. Nueva York: Cambridge University Press.

Gewerc. A. (Coord.). (2010). El lugar de las TIC en la enseñanza universitaria: estudio de casos en Iberoamérica. Málaga: Ediciones Aljibe.

González Rey, F. (2010). El pensamiento de Vygotsky. Repercusiones y consecuencias ausentes en una interpretación dominante. Novedades Educativas, 230, 10-18.

Gros, B. (2016). Retos y tendencias sobre el futuro de la investigación acerca del aprendizaje con tecnologías digitales. RED Revista de Educación a Distancia, 50, 1-13. Recuperado en: http://www.um.es/ead/red/50/gros.pdf

Guevara, G. (2011). Estructura de argumentos. En L. Vega Reñón y P. Olmos (Eds.), Compendio de lógica, argumentación y retórica (pp. 239-243). Madrid: Editorial Trotta.

Hitchcock, D. (2017). On Reasoning and Argument: Essays in Informal Logic and on Critical Thinking. Switzerland: Springer.

Huber, C. R. \& Kuncel, N. R. (2016). Does College Teach Critical Thinking? A Meta-Analysis. Review of Educational Research, 86(2), 431-468. Recuperado en: https://journals.sagepub.com/doi/abs/10.3102/0034654315605917?journalCode=rera

Hughes, W. \& Lavery, J. (2015). Critical Thinking: An Introduction to the Basic Skills. Ontario: Broadview Press. 
Khun, D. (2012). Enseñar a pensar. Buenos Aires: Amorrortu Editores.

Lantz-Andersson, A. (2009). Framing in educational practices. Learning activity, digital technology and the logic of situated action. Göteborg: Acta Universitatis Gothoburgensis.

Lantz-Andersson, A., Linderoth, J. \& Säljö, R. (2009). What's the problem? Meaning making and learning to do mathematical word problems in the context of digital tools. Instructional Science, 37(4), 325343. doi:10.1007/s11251-008-9050-0

Lave, J. (2015). La cognición en la práctica. Buenos Aires: Paidós.

Leontiev, A. (1981). Problems of the development of the mind. Moscú: Progress.

Leontiev, A. (1984) [1978]. Actividad, conciencia y personalidad. México: Editorial Cartago.

Lion, C. (2006). Imaginar con tecnologías. Relaciones entre tecnologías y conocimiento. Buenos Aires: La Crujía.

Litwin, E. (Comp.). (2005). Tecnología educativa en tiempos de internet. Buenos Aires: Amorrortu.

Luppinici, R. (2007). Review of computer mediated communication research for education. Instructional Science, 35, 141-185. doi: 10.1007/s11251-006-9001-6

Maggio, M. (2012). Enriquecer la enseñanza. Los ambientes con alta predisposición tecnológica como oportunidad. Buenos Aires: Paidós.

Matusov, E. (2008). Dialogue with Sociohistorical Vygotskian Academia about Sociocultural Approach. Culture \& Psychology, 14(1), 81-83. doi: 10.1177/1354067X07085814

McPeck, J. E. (2016). Critical Thinking and Education. London: Routledge.

Rockwell, E. (1987). Reflexiones sobre el proceso etnográfico (1982-1985). México: DIE-CINVESTAV-IPN.

Rowe, G., Macagno, F., Reed, C. \& Walton, D. (2006). Araucaria as tool for diagramming arguments in teaching and studying philosophy. Teaching Philosophy, 29(2), 111-124. Recuperado en: https://papers.ssrn.com/sol3/papers.cfm?abstract_id=1751659

Säljö, R. \& Wyndham, J. (2001). Resolución de problemas cotidianos en un ambiente formal: un estudio empírico de la escuela como contexto para el pensamiento. En S. Chaiklin y J. Lave (Comp.), Estudiar las prácticas. Perspectivas sobre actividad y contexto ( $\mathrm{pp}$. 353-367). Buenos Aires: Amorrortu.

Säljö, R., Eklund, A. \& Mäkitalo, A. (2006). Reasoning with mental tools and physical artefacts in everyday problem-solving. En L. Verschaffel, F. Dochy, M. Boekaerts y S. Vosniadou (Eds.), Instructional psychology: past, present, and future trends (pp. 73-90). Oxford: Pergamon.

Sancho Gil, J. (2006). Tecnologías para transformar la educación. Madrid: Akal.

Scheuer, O., Loll, F., Pinkwart, N. \& McLaren, B. (2010). Computer-supported argumentation: a review of the state of the art. International Journal of Computer-Supported Collaborative Learning, 5(1), 43102. doi: $10.1007 / \mathrm{s} 11412-009-9080-x$

Squires, D. \& McDougall, A. (2001). Cómo elegir y utilizar software educativo: guía para el profesorado. Madrid: Morata.

Stake, R. (2010). Investigación con estudio de caso. Madrid: Ediciones Morata.

Tójar Hurtado, J. C. (2006). Investigación cualitativa: Comprender y actuar. España: La Muralla.

Twining, P. (2002). Conceptualising computer use in education: introducing the Computer Practice Framework (CPF). British Educational Research Journal, 28(1), 95-110. doi: $10.1080 / 01411920120109775$

Vigotski, L. (1998). Conductismo. En G. Blanck (Ed.), La genialidad y otros textos inéditos (pp. 87-95). Buenos Aires: Almagesto.

Vygotski, L. (2009) [1978]. El desarrollo de los procesos psicológicos superiores. Buenos Aires: Crítica.

Vygotsky, L. (2010) [1934]. Pensamiento y lenguaje. Buenos Aires: Paidós.

Wenger, E. (2001). Comunidades de práctica: aprendizaje, significado e identidad. Barcelona: Paidós.

Wertsch, J. (1995). Vygotsky y la formación social de la mente. Barcelona: Paidós. 